\title{
Remaining service life prediction of riveted wrought iron railway bridges using system reliability approach
}

\author{
P.B.R. Dissanayake* and P.A.K. Karunananda \\ Department of Civil Engineering, Faculty of Engineering, University of Peradeniya, Peradeniya.
}

Revised: 23 August 2007 : Accepted: 23 October 2007

\begin{abstract}
Over the last decade, structural reliability based analysis and design methods have become widely accepted among researchers and increasingly acknowledged among practicing engineers. A significant amount of research has been performed on condition assessment of existing bridges, yet the data obtained from this research have not been incorporated into the bridge management databases. In fact, there has been considerably little progress in estimation of remaining service life of bridges using this approach. This study proposes methodology to predict the remaining service life and estimate condition of riveted wrought iron railway bridges based on above theory. Initially, based on the field studies and subjective inferences, two failure models are proposed to describe time dependent performances of these bridges. Quantities in the proposed models are assumed to be random variables with appropriate probabilistic distributions. In this context, two proposed models are combined to yield a system reliability model. Then, general methodology is proposed to find out remaining service life and condition estimation based on this system reliability approach. A case study bridge is selected from the national railway network of Sri Lanka and the proposed methodology is demonstrated on the bridge, in order to find out remaining service life of its different components.
\end{abstract}

Keywords: Corrosion, failure probability, fatigue, reliability index, railway bridges, remaining service life

\section{INTRODUCTION}

Many of the engineering structures in today's world are getting old and a large number of this existing stock of civil infrastructure is in need of maintenance, rehabilitation or replacement ${ }^{1}$. Since bridges make up the basic infrastructure affecting all the aspects of society of any country, there is an urgent need to do more research on how to estimate serviceability status and remaining service life estimation of bridges. Although bridge inspection intervals vary around the world ${ }^{2}$, in most countries the current bridge inspection practice is based on judgment in the form of visual inspection ${ }^{3}$. However, to get widespread acceptance among practicing engineers, such methodologies should be based on results of field studies as well as subjective inferences. Furthermore, since there are many uncertainties that exist in such procedures it is essential that any proposed methodology be based on probabilistic approaches to cater for different uncertainties. In this situation, reliability based methods provide a rational approach for using scarce resources efficiently while maintaining a prescribed level of reliability of a structure throughout its designated service life ${ }^{4}$.

Of the different failure modes in riveted wrought iron railway bridges, fatigue and corrosion have been the most vulnerable modes of failure. Fatigue is due to the fluctuating nature of load and corrosion is primarily due to the environmental effects. It is a serious problem because the reduction in the effective steel area causes the increase of member stresses. Corrosion is generally the significant mode of condition deterioration of steel bridges in coastal zones. Despite the fact that many formulations and models have been introduced or proposed at present, how it really affects steel bridges in terms of their remaining service life has not yet been understood clearly. In addition, there is a need to study the combined nature of these two failure models since combination results in lower service life than that arising from an individual failure mode.

This paper proposes reliability-based methodology to find out remaining service life and condition estimation of riveted wrought iron railway bridges. Such a study on how to consider remaining service life in wrought iron railway bridges has rarely been attempted before. In 
addition, both effects of fatigue and corrosion have not been successfully considered. Hence, the objective of this paper is to consider the combined effect of fatigue and corrosion in determination of remaining service life.

\section{METHODS AND MATERIALS}

When a member in a bridge is subjected to cyclic loading in a repetitive manner, it is liable to fail in fatigue, with the operating stresses well below the yield stress. Generally, fatigue is considered to be one of the most significant failure modes of steel bridges.

For a member under fatigue, the failure can be modeled in the reliability approach shown below,

$M_{1}=N_{f}-N_{n}$

Where $M_{1}$ is called the safety margin and it is the criteria used to express how close the failure of the element is. $N_{f}$ is the total number of stress cycles that can be applied to the bridge material and $N_{n}$ is the number of stress cycles that has been applied up to now. Both variables are assumed to behave as random variables having appropriate probabilistic distributions.

When $N_{f} \geq N_{n,} M_{1} \geq 0$ and the member is in the safe region and if $N_{f}<N_{n}, M_{1}<0$ and the member is in the failure region.

Both random variables are normally distributed such that ${ }^{5,6}$

$$
\begin{aligned}
& N_{f} \sim N\left(\mu_{N_{f}}, \sigma_{N_{f}}\right) \\
& N_{n} \sim N\left(\mu_{N_{n}}, \sigma_{N_{n}}\right)
\end{aligned}
$$

As $M_{1}$ is a linearly dependent combination of $N_{f}$ and $N_{n}$,

$$
\begin{aligned}
& \mu_{M_{1}}=\mu_{N_{f}}-\mu_{N_{n}} \\
& \sigma_{M_{1}}^{2}=\sigma_{N_{f}}^{2}+\sigma_{N_{n}}^{2}
\end{aligned}
$$

$\&$ the reliability index

$\beta_{I}=\left(\mu_{N_{f}}-\mu_{N n}\right) / \sqrt{\left(\sigma_{N_{f}}^{2}+\sigma_{N_{n}}^{2}\right)}$

Having found the reliability index, it is then possible to find the failure probability of the element that is subjected to fatigue. The failure probability is given by Equation (3) below.

$$
P_{f_{1}}=-\phi\left[\left(\mu_{N_{f}}-\mu_{N n}\right) / \sqrt{\left(\sigma_{N_{f}}^{2}+\sigma_{N_{n}}^{2}\right)}\right]
$$

For corrosion, the proposed failure mode is shown below,
$M_{2}=\left(A_{s}\right)_{\text {current }}-\left(A_{s}\right)_{\text {required }}$

Where $M_{2}$ is the safety margin, and $\left(A_{s}\right)_{\text {current }}$ is the steel area present at the time of consideration, and $\left(A_{s}\right)_{\text {required }}$ is the steel area required to carry the load on the bridge. When $\left(A_{s}\right)_{\text {current }} \geq\left(A_{s}\right)_{\text {required }}, M_{2} \geq 0$ and the bridge is in a safe condition. When $\left(A_{s}\right)_{\text {current }}<\left(A_{s}\right)_{\text {required }}, M_{2}<0$ and the bridge is in a failure condition.

Both random variables are normally distributed such that 5,6

$$
\begin{aligned}
& \left(A_{s}\right)_{\text {current }} \sim N\left(\mu_{\left(A_{S}\right)_{\text {current }}}, \sigma_{\left(A_{S}\right)_{\text {current }}}\right) \\
& \left(A_{s}\right)_{\text {required }} \sim N\left(\mu_{\left(A_{S}\right)_{\text {required }}}, \sigma_{\left(A_{S}\right)_{\text {required }}}\right)
\end{aligned}
$$

As $M_{2}$ is a linearly dependent combination of $\left(A_{s}\right)_{\text {required }}$ and $\left(A_{s}\right)_{\text {current }}$

$$
\begin{array}{r}
\mu_{M_{2}}=\mu_{\left(A_{S}\right)_{\text {current }}}-\mu_{\left(A_{S}\right)_{\text {required }}} \\
\sigma_{M_{2}}^{2}=\sigma_{\left(A_{S}\right)_{\text {current }}}^{2}+\sigma_{\left(A_{S}\right)_{\text {required }}}^{2} \\
\beta_{2}=\left[\mu_{\left.\left(A_{S}\right)_{\text {current }}-\mu_{\left(A_{S}\right)_{\text {required }}}\right] / .}\right. \\
\sqrt{\left[\sigma_{\left(A_{S}\right)_{\text {current }}}^{2}+\sigma_{\left(A_{S}\right)_{\text {required }}}^{2}\right]}
\end{array}
$$

Having converted $M_{2}$ in to the standard normally distributed variable, failure probability can be expressed as in the equation below.

$$
\begin{gathered}
p_{f_{2}}=-\phi\left\{\left[\mu_{\left(A_{S}\right)_{\text {current }}}-\mu_{\left(A_{S}\right)_{\text {required }}}\right] / .\right. \\
\left.\sqrt{\left[\sigma_{\left(A_{S}\right)_{\text {current }}}^{2}+\sigma_{\left(A_{S}\right)_{\text {required }}}^{2}\right]}\right\}
\end{gathered}
$$

If elementary failure probabilities are known, then total failure probability is $P_{f}$, it can be mathematically represented as follows,

$$
P(M \leq 0)=P\left(M_{1} \leq 0 \cup M_{2} \leq 0\right)
$$

Since $P_{f_{1}}=P\left(M_{1} \leq 0\right), P_{f_{2}}=P\left(M_{2} \leq 0\right), P_{f_{3}}=P\left(M_{1} \cap M_{2} \leq 0\right)$

Then, $P_{f}=P_{f_{1}}+P_{f_{2}}-P_{f_{3}}$

Hence, total failure probability can be found if three components of failure probabilities are known. With a target value of failure probability set, remaining service life and the current condition of the bridge can be determined for the current rate of loading frequency and magnitude. Thus, the estimation of remaining service life is proposed in this study.

Approximate method of determining system failure probability: Total system model represents a series 
system of two components i.e. fatigue and corrosion. Either failure can lead to the failure of the system. In some cases determination of $P_{f_{3}}$, as in Equation 7 may lead to some difficulties. In such cases, a simple bound for this series system can be taken in to account ${ }^{6}$ for determination of remaining service life predictions. Equation 8 below shows the simple bound for the system failure probability from the work of Christensen and Murotsu ${ }^{6}$.

$\underset{i=1}{2} P_{f_{i}} \leq P_{f} \leq 1-\prod_{i=1}^{2}\left(1-P_{f_{i}}\right)$

Special case- no significant corrosion: In bridges where proper maintenance is carried out at suitable time intervals, it is possible to not have a significant effect from corrosion in terms of the overall reliability of the bridge. In such a case, the component failure probabilities relating to corrosion i.e. $P_{f_{2}}$ and $P_{f_{3}}$ can be assumed to be zero and the fatigue effect dominates the overall reliability of the structure.

Target failure probability: Maximum failure probability that a structure can take is dependent on the value of the reliability index as outlined in Equation 9. For any structure, considering their importance, it is not advisable to allow its failure probability to fall beyond a

Table 1: Social criteria factor $(\mu)$ against nature of the structure

$\begin{array}{ll}\text { Nature of the structure } & \mu \\ \text { Places of public assembly, dams } & 0.005 \\ \text { Domestic, office, trade, industry } & 0.05 \\ \text { Bridges } & 0.5 \\ \text { Towers, masts, offshore structures } & 5\end{array}$

certain value. This value of failure probability is termed the target or allowable failure probability of the structure concerned. Hence, allowable failure probability has been defined for different types of structures. Following is the equation proposed by the Construction Industry Research and Information Association (CIRIA) regarding the target failure probability?

$P_{f}=10^{-4} \mu T n^{-1}$,

for a structural design life of $T$ in years. Here $n$ is the average number of people within or near the structure during the period of use and $\mu$ is a social criteria factor as shown in Table I.

By substituting values for Equation 8, the target failure probability of a bridge is obtained as $10^{-5}$. Initially, the failure probability of the bridge is not appreciable. However, with time it increases partially due to the load increment and environmental degradation.

From available literature, there are few studies that have focused on fatigue and corrosion. Nowak and Szerszen ${ }^{8}$ have studied modeling of fatigue and corrosion. In fatigue, they have used the same reliability model as shown in Equation 1. For corrosion effects, three corrosion rates; low, medium and high have been studied. Their effects on moment capacity and shear capacity have been considered. However, the combined effects of fatigue and corrosion have not been studied in detail.

Case study: The selected bridge was one of the longest railway bridges in Sri Lanka spanning $160 \mathrm{~m}$ over two banks of a river situated close to the capital city of Colombo. It is an eight span bridge having Warren type trusses and semi through, double lane rail tracks as shown in Figure I. The bridge was constructed in 1885 and its

Table 2: Variation of number of trains that passed through the bridge over the years (1880-2005)

\begin{tabular}{|c|c|c|c|}
\hline Period & No of trains/day & Remarks & \\
\hline $1995-2005$ & 80 & \multirow{4}{*}{$\begin{array}{l}\text { All engine types and } \\
\text { carriage types are used }\end{array}$} & \\
\hline 1985-1995 & 72 & & \\
\hline $1975-1985$ & 64 & & \\
\hline $1970-1975$ & 56 & & \\
\hline \multirow[t]{4}{*}{$1950-1970$} & 42 & $15 \%$ of $\mathrm{M} 2=\mathrm{M} 1$ & 7 nos \\
\hline & & $30 \%$ of $\mathrm{S} 3=\mathrm{S} 6$ & 13 nos \\
\hline & & $55 \%$ of steam engines & 23 nos \\
\hline & & (this should be divided into three) & \\
\hline $1930-1950$ & 32 & \multicolumn{2}{|l|}{ Only steam engines were divided into $3(12,10,10)$} \\
\hline 1910-1930 & 24 & \multicolumn{2}{|l|}{ Only low weight two steam engine $(12,12)$} \\
\hline $1880-1910$ & 20 & \multicolumn{2}{|l|}{ Steam engines $(10,10)$} \\
\hline
\end{tabular}

M2, M1, S3 and S6 represent different types of train engines used by Sri Lanka Railways ${ }^{9}$. 
piers are made up of cast iron caissons with infilled concrete. Table 2 shows the increase of number of trains over the bridge with time ${ }^{9}$.

Reliability analysis of the bridge: The selected bridge consists of members having different shapes and sections. Nevertheless, these members belong to different sets. In the structural analysis of the bridge, it is important to identify these different sets so that the behaviour of bridge under loading can be interpreted easily with the use of these different member sets. Figure 2 shows the elevation of the truss and its different member sets and Figure 3 shows the plan view of the bridge deck and its member sets ${ }^{9}$. These member sets are categorized considering their sectional area, geometry etc. Out of these different member sets, there are nine sets of members liable to fatigue failure ${ }^{9}$. These are set 2 (main girder), set 3 (main girder), set 4 (main girder), set 8 (cross girder), set 9 (rail bearers), set 6 out (diagonal tension members), set 7 out (diagonal tension members), set 8 out (diagonal tension members), and set 9 out (diagonal tension members) ${ }^{9}$.

The detailed structural analysis of the selected bridge is given in the report by Ranaweera et al. ${ }^{9}$. Life estimation and the current serviceability condition of

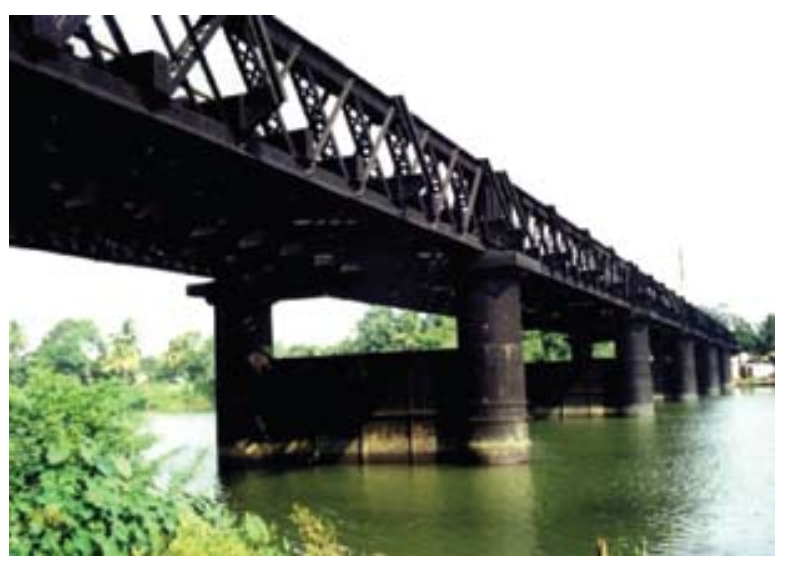

Figure 1: A view of the selected bridge railway bridge members were determined based on the stresses obtained in that study ${ }^{9}$.

Corrosion measurements: In the calculation of the remaining service life of this case study bridge, it was assumed that level of corrosion was not significant. Hence, the probability of the system was calculated due to the effect of fatigue failure that was generated as a result of train movement.

However, using Equations 5 and 6, failure probabilities relating to the corrosion mode of failure could be found in any bridge where the corrosion effect was significant. Furthermore, with the actual corrosion sectional areas input into the Finite Element Model of the bridge failure probability of the combined effect could be found. Using above component failure probabilities substituted in Equation 7, final failure probabilities for each member set could be obtained.

\section{RESULTS AND DISCUSSION}

Summary of the calculations are given in Table 3.

As shown by Table 3, remaining service life of different member sets can be obtained if the present rate of loading,

Table 3: Calculated remaining service life for members of the case study railway bridge

\begin{tabular}{lc}
\hline Member set & $\begin{array}{c}\text { Remaining } \\
\text { due to fatigue }\end{array}$ \\
\hline Set 2 (main girder) & 306 \\
Set 3 (main girder) & 163 \\
Set 4 (main girder) & 163 \\
Set 8 (cross girder) & 25 \\
Set 9 (rail bearers) & 26 \\
Set 6 out (diagonal tension) & 231 \\
Set 7 out (diagonal tension) & 275 \\
Set 8 out (diagonal tension) & 121 \\
Set 9 out (diagonal tension) & 156
\end{tabular}

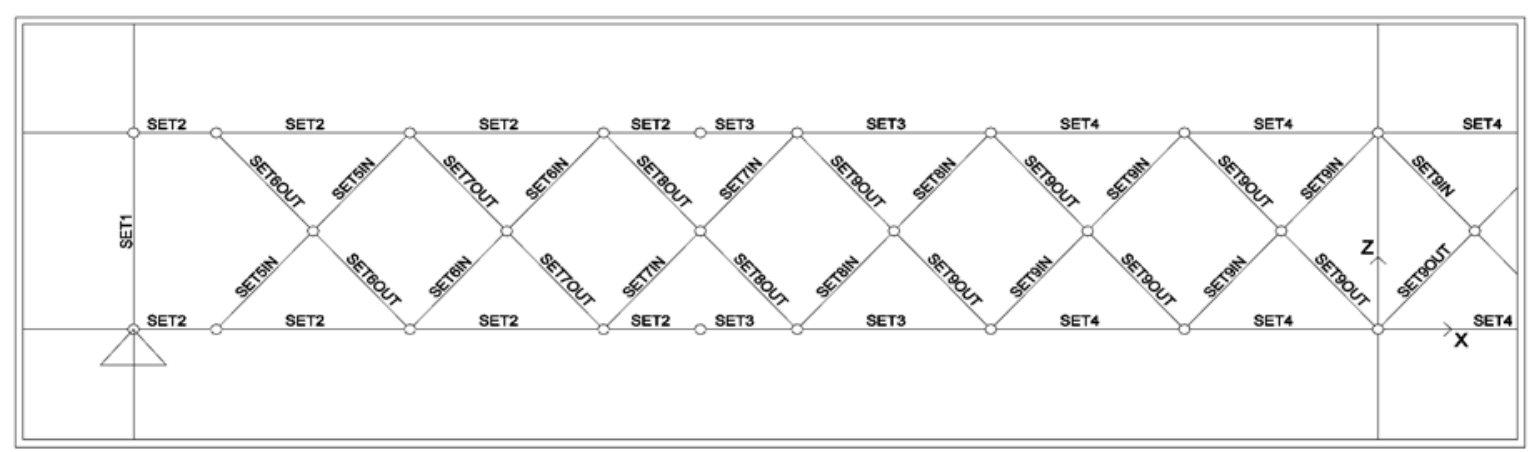

Figure 2: Member set numbering for the truss 


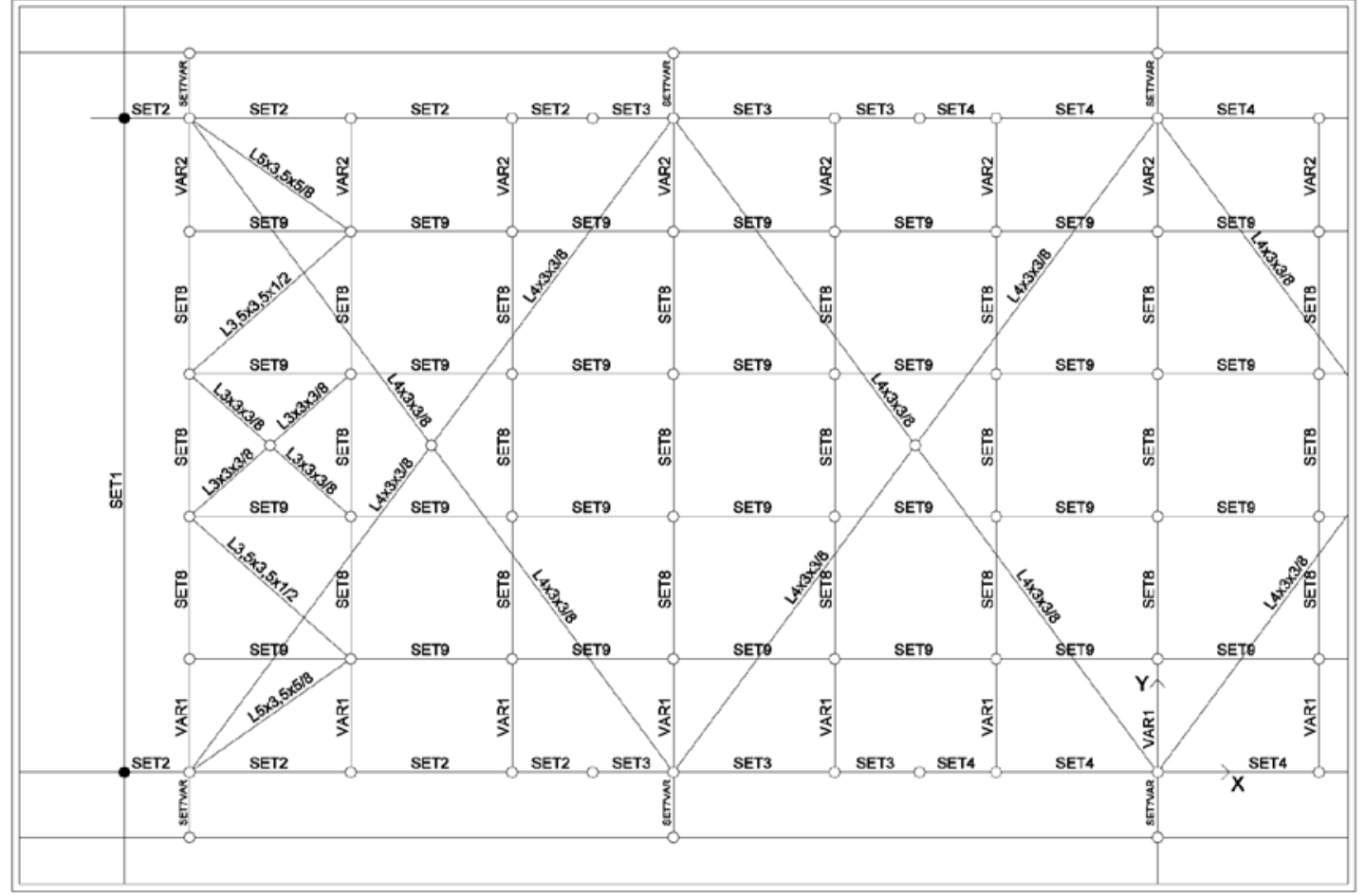

Figure 3: Member set numbering for the bridge deck

magnitude and frequency are followed. Set 8 (cross girder) and Set 9 (rail bearers) have the lowest remaining service life compared to other member sets. These member sets experience higher stresses, thus their remaining service life is low. However, the applied stresses in these two sets are almost of similar magnitude, hence results in almost similar remaining service, life. Other member sets on truss have higher remaining service life as their stresses are low. If corrosion failure is considered, then remaining service life due to the combined failure is lower than that of fatigue failure only.

Regarding maintenance strategy of the bridge, Set 8 (cross girder) and Set 9 (rail bearers) should be checked continuously. At present, the maintenance state of the bridge is satisfactory. However, higher remaining service life for truss member sets should not be looked as a merit point when maintenance is considered. Corrosion should be checked continuously in all members.

The remaining service life values of most of member sets are over 150 years. Nearly same results have been obtained using Miner-Palmgren cumulative damage rule as shown in the work of Ranaweera et al. ${ }^{9}$. Hence, the results obtained from system reliability approach has been verified with an independent study ${ }^{10}$. This shows that bridges can be kept longer in service if proper maintenance is followed. Regarding the original design details of the bridge, at present there are no data available. Therefore, it is impossible to say what British Engineers considered about present corrosion level. However, using this reliability approach, an idea of remaining service life of different member sets can be obtained.

By following the proposed methodology, remaining service life of railway bridge members can be estimated with respect to the combined effect of fatigue and corrosion and hence their condition can be evaluated. This information will help immensely to plan early bridge maintenance and also to identify weaker elements and then replace them with new members. Such an approach will help in reducing the cost expenditure and early planning of new bridges to replace the old ones.

\section{Acknowledgement}

Authors acknowledge the financial assistance provided by the National Science Foundation of Sri Lanka under the grants RG/2002/E/01 and NSF/SCH/2005/02.

\section{References}

1. Kong J.S. \& Frangopol D.M. (2004). Prediction of reliability and cost profile of deteriorating bridges under time and performance-controlled maintenance. Journal of Structural Engineering 130(12):1865-1874. 
2. Sommer A., Nowak A.S. \& Christensen P.T. (1994). Probability based bridge inspection strategy. Journal of Structural Engineering 119(12): 3520-3536.

3. Enright M.P. \& Frangopol D.M. (1999). Condition prediction of deteriorating concrete bridges using Bayesian updating. Journal of Structural Engineering 125(10):1118-1125.

4. Estes A.C. \& Frangopol D.M. (1999). Repair optimization of highway bridges using system reliability approach. Journal of Structural Engineering 125(7): 766 -774.

5. Christensen P.T. \& Baker M. J. (1982). Structural reliability Theory and its Applications, Springer Verlag Publishers, Berlin.

6. Christensen P.T. \& Murotsu Y. (1986). Application of Structural System Reliability Theory, Springer Verlag Publishers, Berlin.
7. Melchers R.E. (1987). Structural Reliability Analysis and Prediction, first edition, Ellis Horwood Publishers, Chichester, West Sussex, England.

8. Nowak A.S. \& Szerszen M.M. (2001). Life Cycle Cost Analysis and Design of Civil Infrastructure Systems, pp. 239-250. American Society of Civil Engineers, USA.

9. Ranaweera M.P., Aberuwan H., Mauroof A.L.M., Herath K.R.B., Dissanayake P.B.R., Siriwardane S.A.S.C. \& Adasooriya A.M.N.D. (2002). Structural appraisal of Railway Bridge at Colombo over Kelani River, Engineering Design Centre, University of Peradeniya, Peradeniya.

10. Karunananda P.A.K., Dissanayake P.B.R. \& Herath K.R.B. (2004). Comparison of Miner-Palmgren Cumulative Damage Rule with Structural Reliability Theory in service lifetime prediction of reverted wrought iron railway bridges, The Sixth Summer Symposium, Saitama University, Japan. 